\title{
Fatores Biocomportamentais e as Alterações no Número das Células de Langerhans
}

\author{
Behavioral Factors and Changes in the Number of Langerhans' cells \\ Nelson Shozo Uchimura ${ }^{1}$, Julisa Chamorro Lascasas Ribalta², José Focchi², \\ Edmund Chada Baracat ${ }^{2}$, Taqueco Teruya Uchimura $^{3}$
}

\begin{abstract}
RESUMO
Objetivos: estudar a relação dos fatores biocomportamentais (idade, menarca, número de gestações e precocidade sexual) com alterações das células de Langerhans em mulheres com captura híbrida negativa para HPV.

Métodos: foram estudadas 30 mulheres com alterações citológicas ou lesão no colo uterino que foram submetidas aos exames de colposcopia, biópsia dirigida e histopatologia. As células de Langerhans foram identificadas pela reação de imuno-histoquímica com uso de antigenos anti-S100. As células visualizadas em marron foram contadas utilizando o software Cytoviewer. Para análise estatística utilizou-se o teste não-paramétrico de soma das ordens de Wilcoxon. Resultados: o número de células de Langerhans em mulheres com menarca após os 13 anos apresentou diferença significante $\left(173,34 \mathrm{cels} / \mathrm{mm}^{2}\right)$ comparado ao grupo com menarca antes de 12 anos $\left(271,41 \mathrm{cel} / \mathrm{mm}^{2}\right)$. A precocidade sexual associou-se ao baixo número de células de Langerhans com 127,15 cels $/ \mathrm{mm}^{2}$ e 250,14 cels $/ \mathrm{mm}^{2}$, respectivamente, para início da atividade até 17 anos e após 17 anos $(p=0,03)$. Cauterizações anteriores do colo uterino foram relacionadas com o menor número de células de Langerhans, no epitélio com a média 120,30 cels $/ \mathrm{mm}^{2}$ e 236,06 cels $/ \mathrm{mm}^{2}$ para aquelas que nunca haviam sido submetidas a esse procedimento $(p=0,05)$. Outros fatores como idade da paciente e número de gestações não foram relacionadas a alteração na densidade de células de Langerhans.

Conclusões: o presente estudo observou associação de fatores biocomportamentais sobre o número das células de Langerhans.
\end{abstract}

PALAVRAS-CHAVE: Colo: lesões pré-neoplásicas. Células de Langerhans. Papilomavírus humano. Atividade sexual. Cauterização do colo. Imunidade celular.

\section{Introdução}

A infecção genital pelo papilomavírus humano (HPV) tem se apresentado como problema de

${ }^{1}$ Departamento de Medicina / Universidade Estadual de Maringá.

${ }^{2}$ Departamento de Ginecologia / Universidade Federal de São Paulo-EPM.

${ }^{3}$ Departamento de Enfermagem / Universidade Estadual de Maringá.

Correspondência:

Nelson Shozo Uchimura

Rua Arthur Thomas 23, apto 901

87013-250 - Maringá - PR

Telefone/Fax: (44) 226-6363

e-mail: nuchimura@irapida.com.br

Projeto desenvolvido na UNIFESP- Hospital São Paulo e financiado pela Fundação Araucária - Programa de Apoio ao Desenvolvimento Científico e Tecnológico do Paraná. suma importância devido a sua alta prevalência e relação com o câncer de colo uterino, estimandose que $34 \%$ das mulheres infectam-se durante suas vidas $^{1,2}$. Essa infecção é geralmente crônica, mesmo na adolescência, quando o sistema imunológico está francamente ativo. A cronicidade da infecção em hospedeiro imunocompetente sugere falha na apresentação do antígeno viral ao sistema imunológico ou no reconhecimento das células HPV infectadas pela reação específica induzida ${ }^{3}$.

A disseminação da infecção pelo HPV, o longo período de latência entre a infecção primária e o desenvolvimento da neoplasia de colo uterino, o pequeno número de indivíduos infectados que desenvolvem o câncer, o alto índice de regressão espontânea e a média de idade das pacientes infectadas (32,4 anos) inferior àquelas com neoplasia inva- 
sora (42,6 anos) sugerem influência de co-fatores na etiologia desse câncer. Entre estes poderíamos citar os fatores imunológicos, fatores hormonais, o fumo e as carências nutricionais de vitamina A, $\beta$-caroteno, vitamina $\mathrm{C}$ e ácido fólico ${ }^{4,5}$.

$\mathrm{Na}$ busca de fatores imunológicos atuantes, têm sido estudados linfócitos T-CD4+, T-CD8+ e células de Langerhans responsáveis pelo reconhecimento das células infectadas ${ }^{6}$. As células de Langerhans são componentes importantes no sistema de vigilância imunológica celular ${ }^{7}$. São células apresentadoras de antígeno que ativam especificamente as células $\mathrm{T}-\mathrm{CD} 4+\mathrm{e}$ além disso exercem ações citotóxicas e fagocíticas diretas típicas de macrófagos ${ }^{8}$. As células de Langerhans, por sua citoarquitetura e sua localização intercelular no terço basal do epitélio escamoso, seriam as responsáveis pela apresentação de antígenos $^{9}$. Evidências de depressão imunológica com diminuição no número de células de Langerhans têm sido relacionadas ao estudo das lesões induzidas pelo HPV no colo uterino ${ }^{10,11}$.

No desenvolver de uma infecção viral ou de um tumor inicia-se a ativação dos linfócitos $\mathrm{T}$ pela apresentação do antígeno ao sistema imunológico. Assim, o mecanismo de apresentação de antígeno viral ou tumoral ao sistema imunológico inicia-se pela sua fagocitose pelas células de Langerhans nas quais é processado, associado às moléculas do complexo de histocompatibilidade principal (MHC) e, a seguir, exposto ao linfócito T específico ${ }^{12}$.

A suscetibilidade à infecção viral e fúngica recorrente em mulheres HIV-positivas é explicada pela baixa imunidade celular local. Assim, foi demonstrada em biópsia de colo uterino diminuição do número das células de Langerhans, dos linfócitos CD4+ e dos plasmócitos, bem como aumento dos números de linfócitos CD8+, mesmo quando estas alterações não são detectadas no sangue periférico ${ }^{13}$.

Como evidência da importância das células de Langerhans junto ao sistema de imunovigilância antitumoral, observou-se estar a sua depleção associada ao aumento de incidência de tumores de epitélio escamoso, em pacientes submetidas à irradiação ultravioleta e à corticoterapia ${ }^{14}$.

Tay et al. ${ }^{15}$, ao estudarem as células de Langerhans com diversos marcadores, observaram tanto nas infecções por HPV quanto em neoplasia intraepitelial cervical (NIC) redução do seu número em 60\% com marcadores OKT6, ATPase e HLADR, enquanto havia depleção completa de células $\mathrm{S} 100+$. Estes achados sugerem que a depleção seletiva de células $\mathrm{S} 100+$ pode ser a causa da imunodeficiência localizada.

Em estudos semelhantes, al-Saleh et al. ${ }^{6}$ confirmaram redução do número de células de Langerhans no epitélio metaplásico e em NIC in- dependentemente do tipo de HPV causador da infecção. O epitélio glandular da área de metaplasia parece inibir a migração das células de Langerhans, tornando essa área de risco para desenvolvimento de neoplasia não só pelo fato de ser local de instabilidade tecidual, mas também pela diminuição das células apresentadoras de antígenos.

Estudos ressaltam a influência do HPV na etiopatogenia da neoplasia da cérvice uterina associadas a múltiplos co-fatores extrínsecos e endógenos do hospedeiro, como: fatores imunológicos, hormonais e o fumo ${ }^{16}$. A imunidade local, mediada pelas células de Langerhans, pode ser a chave do mecanismo defensivo do hospedeiro contra infecção por HPV e contra o desenvolvimento de carcinoma cervical.

O objetivo deste trabalho foi determinar se os fatores como idade, menarca, número de gestações e precocidade sexual estão associados às alterações do número das células de Langerhans no colo uterino.

\section{Pacientes e Métodos}

Foram incluídas 30 mulheres atendidas no ambulatório da Clínica da Mulher da Secretaria de Saúde do Município de Maringá (PR) no período de agosto de 1999 a novembro de 2001, que apresentavam amostras de colo uterino negativas para HPV pelo método da captura híbrida.

As pacientes com alterações citológicas ou lesão no colo uterino e exame de captura híbrida negativa foram incluídas no estudo. Foram excluídas as gestantes, lactantes e menopausadas, as usuárias de imunossupressores e de imunoestimuladores nos últimos três meses, bem como as usuárias de drogas e de narcóticos, além das portadoras de doenças auto-imunes, de neoplasias e de diabete.

O presente estudo foi aprovado pela Comissão de Ética Médica do Hospital São Paulo - Universidade Federal de São Paulo. As pacientes foram previamente esclarecidas quanto aos objetivos da pesquisa. Após a concordância das mesmas, o consentimento foi formalizado mediante a assinatura do termo de consentimento livre e informado.

No atendimento inicial foi realizada entrevista seguida do preenchimento da ficha clínica específica para o estudo e agendamento de retorno para a primeira fase do ciclo menstrual a fim de efetuar a biópsia dirigida pela colposcopia.

As biópsias foram efetuadas sob orientação colposcópica com pinças Gaylor-Medina e cada uma das amostras subdivididas em outras duas partes: a primeira, encaminhada ao exame ana- 
tomopatológico e imuno-histoquímico, e a segunda, colocada em tubo de coleta especial contendo $1 \mathrm{~mL}$ de azida sódica 0,05\% (Digene Diagnostics Inc.) e congelada a $-20^{\circ} \mathrm{C}$, e posteriormente encaminhada ao laboratório. A técnica utilizada para detecção de material genético viral foi a hibridização molecular, por captura de híbridos em microplaca. São empregadas sondas não radioativas, com amplificação da detecção dos híbridos por quimioluminescência. Essa técnica permite diagnosticar os 18 tipos mais comuns de HPV do trato genital e classificar o HPV em dois grandes grupos, o do tipo A, baixo risco (tipos $6,11,42,43$, 44) e do tipo B, alto risco (tipos 16, 18, 31, 33, 35, $39,45,51,52,56,58,59,68)$. A sensibilidade do teste para o HPV é maior ou igual a $1,0 \mathrm{pg} / \mathrm{mL}$ DNA-HPV ${ }^{17}$.

A reação imuno-histoquímica para as células $\mathrm{S} 100+$ foi efetuada conforme os princípios propostos por Hsu e Raine ${ }^{18}$. Cada amostra teve, em média, cinco cortes histológicos de 3 a 4 micra distribuídos em lâminas silanizadas e incubadas com anticorpo preparado em coelho (anticorpo S100 - Dako), em solução 1/5000, diluído em solução de albumina a $1 \%$ e azida sódica $\left(\mathrm{NaN}_{3}\right)$ a $0,1 \%$ em solução tamponada com fosfato (PBS). A seguir, os cortes foram incubados com anticorpo de cabra anti-coelho, biotinilado (Vector Laboratories) e foi aplicado o complexo estreptavidina-biotinaperoxidase. A reação foi revelada com substrato cromogênico por 3 a 5 minutos, preparado com diaminobenzidina (Sigma, USA) a 0,6\%, peróxido de hidrogênio a 0,06\% e dimetilsulfóxido a $1 \%$ em PBS. Os cortes assim preparados foram contracorados com hematoxilina de Harris e montados em Entellan (Merck) com lamínulas.

As células de Langerhans S100+ foram identificadas pela coloração marrom de seus citoplasmas, que se apresentavam, conforme o eixo do corte histológico, em perfis citoplasmáticos de diversas formas como de ponto, vírgula, filiforme ou mesmo arboriforme.

Cada lâmina assim preparada foi avaliada num microscópio de luz com 400 vêzes de aumento, adaptado a microcâmera, e sua imagem digitalizada pelo software Cytoviewer. O cálculo da área em micrômetros quadrados por campo foi feito previamente, utilizando a câmara graduada de Neubauer. Conhecida a área examinada por campo, contou-se o número das células de Langerhans por meio da contagem de núcleos celulares e de perfis citoplasmáticos por milímetro quadrado. As observações das características qualitativas dos elementos celulares foram estudadas e também melhor visualizadas no monitor de computador. Quantificaram-se também as células de Langerhans de acordo com sua localização nas camadas do epitélio ou do estroma, conforme a divisão histológica do epitélio escamoso em camadas superficial, intermediária e basal ${ }^{19}$.

Para análise estatística calcularam-se a média aritmética e os respectivos desvios-padrão do número das células de Langerhans por milímetro quadrado. Utilizou-se o teste não paramétrico de soma das ordens de Wilcoxon (rank sum test) e considerou-se o nível de rejeição da hipótese de nulidade de $5 \%(\mathrm{p}<0,05)^{20}$.

\section{Resultados}

Foram estudados os fragmentos de colo uterino de 30 mulheres com a faixa etária de 18 a 46 anos e média de 30 anos. Do total das mulheres, $6(20,0 \%)$ estavam fazendo o exame preventivo de câncer pela primeira vez.

Pela observação quantitativa ao microscópio, verificou-se a presença de células de Langerhans tanto no epitélio como no estroma subjacente, sendo mais freqüente no epitélio. Observou-se ainda a localização preferencial dessas células na camada basal e na intermediária, sendo rara a presença na camada superficial do epitélio.

Ao analisar o parâmetro idade da paciente, categorizaram-se as mulheres em grupos com menos de trinta anos ( $\mathrm{n}=14-46,6 \%)$ e com mais de 30 anos ( $n=16-53,6 \%)$. As pacientes com menos de 30 anos apresentavam média das células de Langerhans de $252,80 \mathrm{cel} / \mathrm{mm}^{2}$ e as com mais de 30 anos, a média igual a $185,24 \mathrm{~mm}^{2}$, sendo esta diferença não significante $(\mathrm{p}=0,06)$. $\mathrm{O}$ mesmo ocorreu no estudo por camadas histológicas, pois as médias dos números das células não apresentaram diferenças estatisticamente significantes.

Quanto ao início da idade fértil, $10(33,3 \%)$ mulheres apresentaram menarca antes de 12 anos e 20 (66,7\%), após os 13 anos. Verificou-se que para as mulheres com menarca após os 13 anos o número de células de Langerhans apresentou diferença significante, com média de $173,34 \mathrm{cel} / \mathrm{mm}^{2}$, comparada ao outro grupo, com $271,41 \mathrm{cel} / \mathrm{mm}^{2}$ (Tabela 1 ). A redução no número das células de Langerhans ocorreu em todas as camadas histológicas do epitélio.

Quanto à precocidade sexual, o início de relações sexuais antes de 17 anos foi referida por $11(36,7 \%)$ mulheres e relacionou-se com menor número das células de Langerhans no epitélio do colo uterino, com médias de $127,15 \mathrm{cel} / \mathrm{mm}^{2} \mathrm{e}$ $250,14 \mathrm{cel} / \mathrm{mm}^{2}$, respectivamente, para início da atividade sexual até 17 anos e após 17 anos $(p=0,03)$. Essas alterações ocorreram nas camadas intermediária e basal do epitélio, pois na camada superficial a densidade apresentou apenas uma tendência à queda (Tabela 2). 
Tabela 1 - Número de células de Langerhans por $\mathrm{mm}^{2}$ (densidade) nas camadas superficial, intermediária e basal do epitélio do colo. Distribuição de acordo com a idade da menarca (médias e desvios padrão).

\begin{tabular}{|c|c|c|c|c|c|}
\hline \multicolumn{2}{|l|}{ Epitélio } & \multicolumn{2}{|c|}{ Menarca } & \multirow[b]{2}{*}{$(n=20)$} & \multirow[b]{3}{*}{$p$} \\
\hline Camadas histológicas & $\leq=12 \mathrm{anos}$ & $(n=10)$ & $\geq=13$ anos & & \\
\hline & Média & DP & Média & DP & \\
\hline Superficial & 10,0 & 9,6 & 6,8 & 18,5 & $0,01^{*}$ \\
\hline Intermediária & 168,9 & 106,4 & 81,0 & 80,3 & $0,01^{*}$ \\
\hline Basal & 47,2 & 36,6 & 19,4 & 25,5 & $0,01^{*}$ \\
\hline Todas as camadas & 271,4 & 112,6 & 173,3 & 162,9 & $0,02^{*}$ \\
\hline
\end{tabular}

*Teste de Wilcoxon (rank sum test).

Tabela 2 - Número de células de Langerhans por $\mathrm{mm}^{2}$ (densidade) nas camadas superficial, intermediária e basal do epitélio do colo. Distribuição de acordo com a idade de início da atividade sexual (médias e desvios padrão).

\begin{tabular}{|c|c|c|c|c|c|}
\hline \multirow{2}{*}{$\begin{array}{l}\text { Epitélio } \\
\text { Camadas histológicas }\end{array}$} & \multicolumn{4}{|c|}{ Início da atividade sexual } & \multirow[b]{3}{*}{$p$} \\
\hline & $\leq 17$ anos & $(n=11)$ & $\geq 18 a n o s$ & $(n=19)$ & \\
\hline & Média & DP & Média & DP & \\
\hline Superficial & 4,0 & 9,2 & 10,5 & 19,2 & 0,08 \\
\hline Intermediária & 54,6 & 67,2 & 141,2 & 101,9 & $0,01^{*}$ \\
\hline Basal & 19,0 & 32,3 & 33,8 & 31,9 & $0,04^{*}$ \\
\hline Todas as camadas & 127,1 & 111,6 & 250,1 & 164,0 & $0,03^{*}$ \\
\hline
\end{tabular}

*Teste de Wilcoxon (rank sum test).

Quanto ao número de gestações, observaram-se 11 (36,6\%) nuligestas e 19 (63,4\%) primigestas ou mais. Não houve diferença estatisticamente significante nas médias de densidade das células de Langerhans tanto no epitélio quanto em camadas histológicas, entre mulheres que haviam engravidado pelo menos uma vez comparadas às nuligestas.

As cauterizações prévias do colo uterino referidas por $5(16,7 \%)$ mulheres foram associadas a menor número das células no epitélio, com a média de $120,30 \mathrm{cel} / \mathrm{mm}^{2}$ e $236,06 \mathrm{cel} / \mathrm{mm}^{2}$ para aquelas que nunca se submeteram a esse tratamento $(p=0,05)$. Essas alterações foram observadas principalmente nas camadas intermediária e basal (Tabela 3).

Tabela 3 - Número de células de Langerhans por $\mathrm{mm}^{2}$ (densidade) nas camadas superficial, intermediária e basal do epitélio do colo. Distribuição de acordo com antecedentes de cauterizações (médias e desvios padrão).

\begin{tabular}{lrrrrr}
\hline Epitélio & \multicolumn{5}{c}{ Antecedentes de Cauterizações } \\
Camadas histológicas & Não $(\mathbf{n}=\mathbf{2 5})$ & Sim $(\mathbf{n}=5)$ & \\
& Média & DP & Média & DP & p \\
\hline Superficial & 8,3 & 16,8 & 2,8 & 6,3 & 0,10 \\
Intermediária & 125,1 & 97,7 & 53,9 & 56,9 & $0,03^{*}$ \\
Basal & 32,7 & 32,0 & 9,9 & 11,7 & $0,04^{*}$ \\
Todas as camadas & 236,0 & 161,1 & 120,3 & 81,7 & $0.05^{*}$ \\
\hline${ }^{*}$ Teste de Wilcoxon (rank sum test). & & & &
\end{tabular}

\section{Discussão}

Múltiplos fatores etiopatogênicos do câncer de colo uterino foram estudados. No entanto, o comportamento sexual como a precocidade sexual, a idade da primeira gravidez e a promiscuidade sexual apresentam-se como fatores determinantes ${ }^{21,22}$. Observam-se evidências do comprometimento das células de Langerhans em pacientes com HPV persistente ou em neoplasia intra-epitelial cervical. As células de Langerhans e os linfócitos apresentamse como componentes importantes nessa imunovigilância, pois enquanto as primeiras atuam como células apresentadoras de antígeno, ativando especificamente as células T-CD4+, os linfócitos exercem ações citotóxica e fagocítica ${ }^{7,8}$.

O período de latência longo da infecção por HPV e a idade mais prevalente para o desenvolvimento do câncer de colo uterino sugerem a existência de co-fatores biocomportamentais na etiopatogenia deste tumor ${ }^{4,5}$. Dessa forma a idade da paciente parece ter influência sobre os fatores imunológicos. Neste estudo observou-se tendência à diminuição da média do número das células de Langerhans em mulheres com mais de 30 anos. Segundo Tindle e Frazer ${ }^{3}$, a adolescência caracteriza-se pelo sistema imunológico francamente ativo, observado também neste estudo, e pressupõe-se a ocorrência de depressão das células de 
Langerhans com o aumento da idade, predispondo à oncogênese do colo uterino.

A alta taxa de regressão da infecção por HPV e a evolução de alguns casos para malignização sugerem a existência de outros fatores associados à imunodepressão, tais como a irradiação, fumo e hormônios ${ }^{4,23}$. A influência dos hormônios na imunidade tem sido referida pela observação da alta prevalência de HPV e diminuição do número das células de Langerhans na gestação ${ }^{24}$. O aumento da taxa de infecção pelo HPV na gestação pode ser pela ação hormonal direta sobre o DNAHPV na expressão dos genes virais E6 e E7. Essa ação hormonal também existe nos genes reguladores do ciclo celular responsáveis pela apoptose, inibindo tanto a proteína p53 ou diretamente as células de Langerhans ${ }^{25}$. Este estudo não encontrou diferença quanto ao número de células de Langerhans em relação aos antecedentes de gestação, provavelmente por serem essas alterações hormonais de efeito transitório próprio da gravidez. Por outro lado, observou-se que a menarca após os 13 anos está associada ao pequeno numero das células de Langerhans, sugerindo que a menarca tardia pode representar desequilíbrio na homeostase hormônio-imunidade que persiste durante a menacme ou mesmo interfere na maturação funcional das células de Langerhans.

A liberação sexual trouxe muitas conseqüências para a saúde da mulher, sendo a precocidade sexual um dos importantes fatores associados tanto à infecção pelo HPV quanto ao câncer de colo uterino ${ }^{22}$. Observou-se associação da precocidade sexual com o menor número das células de Langerhans, sugerindo que a ação dos componentes do sêmen conjuntamente com outros agentes oncogênicos, em face do epitélio cervical imaturo, poderia desencadear imunodepressão com redução do número destas células. A influência da precocidade sexual sobre as células de Langerhans não ficou claramente definida.

Considerada como um estado funcional fisiológico da mulher, a ectopia do colo era, até há pouco tempo, definida como lesão benigna do colo, e a cauterização, o seu tratamento de eleição. Estudos têm demonstrado ser esse procedimento uterino responsável pela diminuição do número das células de Langerhans ${ }^{26}$. Confirmando esses achados, foi observada redução para um terço no número das células em mulheres submetidas a esse tipo de procedimento médico. A repercussão clínica desta redução não é evidente. No entanto, ela pode estar relacionada à reação fibrótica induzida no colo pós-cauterização, dificultando a migração celular. Os métodos como a eletrocauterização, cirurgia de alta freqüência, laserterapia e quimiocauterização são ablativos mas não preservam as células do sistema imunológico.

No presente estudo observamos associação dos fatores biocomportamentais como a idade da menarca, precocidade sexual e antecedentes de cauterizações de colo uterino com a diminuição do número das células de Langerhans. Este estado de imunodepressão local favorece a infecção pelo vírus na camada basal, onde sua proliferação atinge os queratinócitos da camada intermediária com inibição de citocina IL-2 e liberação de citocina IL10, que agravam ainda mais a depressão dessas células ${ }^{27}$. Essa ação conjunta da imunodepressão por fatores biocomportamentais e do HPV nas células do epitélio cervical pode contribuir para início da oncogênese; assim, estudos mais detalhados devem ser realizados para esclarecer a influência desses determinantes da imunodepressão e aprimorar ainda mais os programas de prevenção e de tratamento das neoplasias de colo uterino.

\section{ABSTRACT}

Objective: to study the relationship of biobehavioral factors, such as age, menarche, number of gestations, and age of first sexual intercourse, with changes in Langerhans'cells in women with negative hybrid capture for $H P V$.

Methods: thirty women referred due to abnormal cervical cytology or premalignant cervical lesions were studied and underwent colposcopy, guided biopsy and histopathological exams. The Langerhans' cells were identified by immunohistochemical (S100+) exams. Langerhans' cells visualized in brown color were counted using the software Cytoviewer. The nonparametric Wilcoxon rank-sum test was employed for statistical analysis.

Results: the number of Langerhans' cells in women who had menarche after 13 years old presented statistically significant difference $\left(173.34 \mathrm{cell} / \mathrm{mm}^{2}\right)$ compared to the group whose menarche occurred before $13\left(271.41 \mathrm{cell} / \mathrm{mm}^{2}\right)$. The age at the first sexual intercourse was associated with the low number of Langerhans' cells, $127.15 \mathrm{cell} / \mathrm{mm}^{2}$ and 250.14 cell/ $\mathrm{mm}^{2}$, respectively, for the beginning of the sexual activity up to 17 years old and after $17(p=0.03)$. Previous cauterizations of the uterine cervix have been related to a lower number of Langerhans' cells in the epithelium, with the average $120.30 \mathrm{cell} / \mathrm{mm}^{2}$ as compared to $236.06 \mathrm{cell} / \mathrm{mm}^{2}$ for those women who never underwent that procedure $(p=0.05)$. Other factors such as the patient's age and the number of gestations showed no statistically significant differences in the density of Langerhans' cells.

Conclusions: the present study reports the association of biobehavioral factors with decrease in the number of Langerhans' cell.

KEYWORDS: Cervix: neo-plastic lesions. Langerhans' cells. Human papillomavirus. Sexual activity. Cervical cauterizations. Celular immunization. 


\section{Referências}

1. de Villiers EM, Wagner D, Schneider A, et al. Human papillomavirus DNA in women without and with cytological abnormalities: results of a 5-year followup study. Gynecol Oncol 1992; 44:33-8.

2. Smotkin D. Human papillomavirus infection of the vagina. Clin Obstet Gynecol 1993; 36:188-94.

3. Tindle RW, Frazer IH. Immune response to human papillomaviruses and the prospects for human papillomavirus-specific immunisation. Curr Top Microbiol Immunol 1994; 186:217-53.

4. zur Hausen H. Human genital cancer: synergism between two virus infections or synergism between a virus infection and initiating events? Lancet 1982; $2: 1370-2$.

5. De Palo G, Vecchione A. Neoplasia intraepitelial do colo uterino. In: De Palo G, editor. Colposcopia e Patologia do Trato Genital Inferior. $1^{\text {a }}$ ed. Rio de Janeiro: Médica e Científica; 1993. p.223-65.

6. al-Saleh W, Giannini SL, Jacobs N, et al. Correlation of T-helper secretory differentiation and types of antigen-presenting cells in squamous intraepithelial lesions of the uterine cervix. J Pathol 1998; 184:283-90.

7. Poppe WA, Drijkoningen M, Ide PS, Lauweryns JM, Van Assche FA. Lymphocytes and dendritic cells in the normal uterine cervix. An immunohistochemical study. Eur J Obstet Gynecol Reprod Biol 1998; 81:277-82.

8. Cohn ZA. The activation of mononuclear phagocytes: fact, fancy, and future. J Immunol 1978; 121:813-6.

9. Roig de Vargas-Linares C. Langerhans cells and Tlymphocytes in the normal human ectocervix defined by monoclonal antibodies and electron microscopy. Microsc Eletron Biol Celular 1989; 13:53-63.

10.Uchimura NS. Alterações das células de Langerhans e sua relação com lesão hispatológica do colo uterino por papilomavírus humano em pacientes com captura híbrida positiva [tese]. São Paulo: Univ. Federal de São Paulo; 2002.

11.Palaoro LA, Rocher AE, Blanco AM. Células de Langerhans y lesiones intraepiteliales de cuello uterino. Acta Bioquim Clin Latinoam 2002; 36:51-6.

12.Austyn JM. Lymphoid dendritic cells. Immunology 1987; 62:161-70.

13. Olaitan A, Johson MA, MacLean A, Poulter LW. The distribution of immunocompetent cells in the genital tract of HIV-positive women. AIDS 1996; 10:759-64.

14.Belsito DV, Flotte TJ, Lim HW, Baer RL, Thorbecke GJ, Gigli I. Effect of glucocorticosteroids on epidermal Langerhans cells. J Exp Med 1982; 155:291-302.
15.Tay SK, Jenkins, D, Maddox P, Campion M, Singer A. Subpopulations of Langerhans' cells in cervical neoplasia. Br J Obstet Gynaecol 1987; 94:10-5.

16.Winer RL, Lee SK, Hughes JP, Adam DE, Kiviat NB, Koutsky LA. Genital human papillomavirus infection: incidence and risk factors in a cohort of female universtity students. Am J Epidemiol 2003; 157:218-26.

17.Lorincz AT. Molecular methods for the detection of human papillomavirus infection. Obstet Gynecol Clin North Am 1996; 23:707-30.

18.Hsu SM, Raine L. The use of avidin-biotinperoxidase $(\mathrm{ABC})$ in diagnostic and research pathology. In: De Lellis RA, editors. Advances in Immunohistochemistry. $1^{\text {st }}$ ed. New York: Masson; 1984. p.31-42.

19.Silva Filho AM, Bassi RA. Anatomia microscópica do colo uterino humano. In: Silva Filho AM, editor. O Colo Uterino Humano. $1^{\text {a }}$ ed. São Paulo: Artes Médicas; 1991. p. 29-87.

20.Campos H. Estatística experimental nãoparamétrica. 4⿳⺈ ed. Piracicaba: Ed. Esalq; 1983. p.349.

21.Paal MAF. Contribuição para o estudo das relações entre imagens colposcópicas e atividade sexual em jovens com idade até 18 anos [tese]. São Paulo: Escola Paulista de Medicina; 1974.

22.Focchi J. Influência da gestação e do parto na localização da zona de transformação atípica colposcópica [dissertação]. São Paulo: Escola Paulista de Medicina; 1983.

23. Hildesheim A, Reeves WC, Brinton LA, et al. Association of oral contraceptive use and human papillomaviruses in invasive cervical cancers. Int $\mathrm{J}$ Cancer 1990; 45:860-4.

24.Poppe WA, Peeters R, Drijkoningen M, et al. Cervical cotinine and macrophage-Langerhans cell density in the normal human uterine cervix. Gynecol Obstet Invest 1996; 41:253-9.

25.von Knebel-Doeberitz M, Spitkovsky D, Ridder R. Interactions between steroid hormones and viral oncogenes in the pathogenesis of cervical cancer. Verh Dtsch Ges Pathol 1997; 81:233-9.

26. Câmara PAD, Simões PM. Aspectos histopatológicos e imunopatológicos do colo uterino antes e após eletrocauterização. Rev Bras Ginecol Obstet 1994; 16:59-67.

27.Giannini SL, Hubert P, Doyen J, Boniver J, Delvenne P. Influence of the mucosal epithelium microenvironment on Langerhans' cells: implications for the development of squamous intraepithelial lesions of the cervix. Int J Cancer 2002; 97:654-9. 